\title{
Status of the gyrotron complex for ITER: composition of the complex, manufacturing, obtained parameters, delivery conditions
}

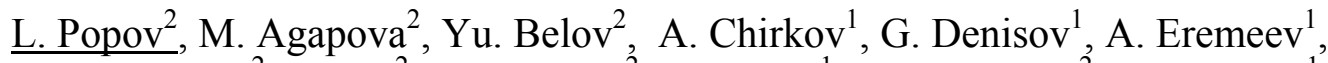 \\ A. Gnedenkov', V. Ilin ${ }^{2}$, A. Kuzmin ${ }^{2}$, A. Litvak ${ }^{1}$, A. Lyubimov ${ }^{2}$, V. Malygin ${ }^{1}$, \\ V. Miasnikov ${ }^{2}$, V. Nichiporenko ${ }^{2}$ E. Sokolov ${ }^{1}$, E. Soluyanova ${ }^{2}$, E. Tai ${ }^{2}$, S. Usachev ${ }^{2}$, \\ V. Usov' ${ }^{1}$, V. Zapevalov ${ }^{1}$ \\ ${ }^{1}$ Institute of Applied Physics RAS, Nizhny Novgorod, Russia \\ ${ }^{2}$ Gycom Ltd., Nizhny Novgorod, Russia
}

IAP RAS in cooperation with Gycom Ltd. prolongs manufacturing of gyrotron systems (RF power sources) for ITER under contract \#17706413348180000850/45-320 of the 27.04.2018 with Russian DA “ITER Center". Serial production had started after approval of Final design review in December 2016 following by approval of Manufacturing readiness review (MRR) in April 2017. MRR confirmed that Gycom has all necessary facilities for full cycle of gyrotron production: machining, brazing, assembling, exhausting and testing.

Since that time two gyrotron systems were completed and successfully put through acceptance test meeting ITER specifications (see[1, 2]). Additional $1 \mathrm{MW} / 170 \mathrm{GHz} / 1000 \mathrm{~s}$ gyrotron identical to serial one was produced by Gycom under request of F4E and shipped to Swiss Plasma Center facility in Lausanne after acceptance test carried out at Gycom with participation of F4E representatives in April 2017.

Gyrotron system components will be located on $2^{\text {nd }}$ and $3^{\text {rd }}$ floors of ITER building B15 as schematically shows this picture.

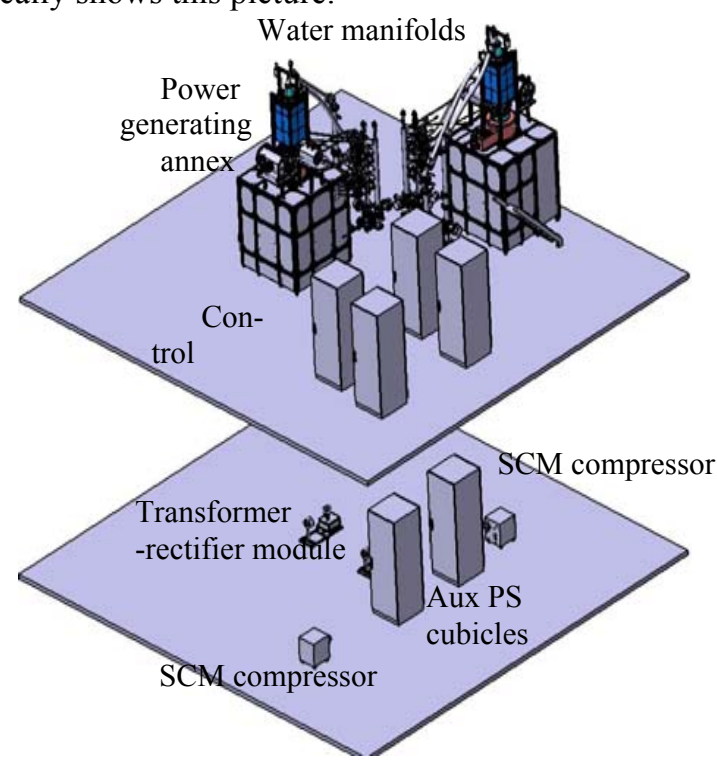

Fig. 1 Schematic view of gyrotron system components location at ITER site

Power generating annex is the core of gyrotron system which is directly produced by Gycom. List of its deliverable components of includes at present 25 items. It does not include components of control sys- tem which stays a bit separately due to multiple issues associated mainly with permanent changes made by ITER organization (IO) in hardware and software. Test of the first two serial RF power sources as was agreed with IO were performed using prototype control system which essentially deviates from today's version. Its latest embodiment is to be manufactured this summer and tested in autumn together with fabric test of the $3^{\text {rd }}$ serial gyrotron system.

\section{Test results}

At the factory acceptance test at Gycom two serial gyrotron as well as their analogue produced for F4E demonstrated very similar output parameters accumulated in following table

\begin{tabular}{|l|c|c|c|}
\hline \multicolumn{1}{|c|}{$\begin{array}{c}\text { Gyrotron } \\
\text { Parameters }\end{array}$} & $\begin{array}{c}\text { 1st serial } \\
\text { gyrotron }\end{array}$ & $\begin{array}{c}\text { Gyrotron } \\
\text { for F4E }\end{array}$ & $\begin{array}{c}2^{\text {nd }} \text { serial } \\
\text { gyrotron }\end{array}$ \\
\hline Frequency, GHz & $169.9 \pm 03$ & 170 & $169.9 \pm 03$ \\
\hline $\begin{array}{l}\text { RF output power, } \\
\text { MW }\end{array}$ & $0.97 \pm 0.05$ & 0.92 & $0.96 \pm 0.05$ \\
\hline $\begin{array}{l}\text { Output radiation - } \\
\text { HE mode con- } \\
\text { tent, \% }\end{array}$ & $97.3 \pm 0,5$ & 96.8 & $\begin{array}{c}\text { Waiting } \\
\text { for meas- } \\
\text { urement }\end{array}$ \\
\hline $\begin{array}{l}\text { Efficiency (with } \\
\text { depressed collec- } \\
\text { tor), \% }\end{array}$ & $56 \pm 3$ & 56.3 & $53 \pm 3$ \\
\hline Pulse duration, sec & 1000 & $400 / 1000$ & 1000 \\
\hline Beam voltage, kV & $42.5 \pm 0.4$ & $42.5 \pm 0.4$ & $44.1 \pm 0.4$ \\
\hline $\begin{array}{l}\text { Depression volt- } \\
\text { age, kV }\end{array}$ & $27.5 \pm 0.3$ & $28.5 \pm 0.3$ & $26.5 \pm 0.3$ \\
\hline Beam current, A & $42 \pm 0.2$ & $37.5 \pm 0.2$ & $42.4 \pm 0.2$ \\
\hline Body current, mA & $10 \pm 0.1$ & $<20$ & $14 \pm 0.1$ \\
\hline Reliability, \% & $>95$ & $>80$ & $>95$ \\
\hline
\end{tabular}

Test program of serial gyrotrons included:

- 4 pulses $1 \mathrm{MW} / 1000 \mathrm{~s}$ at duty cycle 0.25

- 10 pulses $1 \mathrm{MW} / 75 \mathrm{~s}$ at duty cycle 0.05

- 40 pulses $1 \mathrm{MW} / 100 \mathrm{~s}$ at duty cycle 0.25

- 20 pulses $1 \mathrm{MW} / 500 \mathrm{~s}$ at duty cycle 0.25

- 3 pulses $1 \mathrm{MW} / 200 \mathrm{~s}$ ON/OFF modulated $/ 100 \mathrm{~Hz}$

- 3 pulses $1 \mathrm{MW} / 200 \mathrm{~s}$ ON/OFF modulated / $500 \mathrm{~Hz}$ - 3 pulses $1 \mathrm{MW} / 200 \mathrm{~s}$ ON/OFF modulated/1000 Hz Pictures below illustrate recent test results of second serial gyrotron in more details. Fig. 2 shows signal traces monitored during one of $1 \mathrm{MW} / 1000$ s pulse and 
graphs on the Fig. 3 give statistics of power and frequency measurements for $500 \mathrm{~s}$ and $1000 \mathrm{~s}$ pulses.

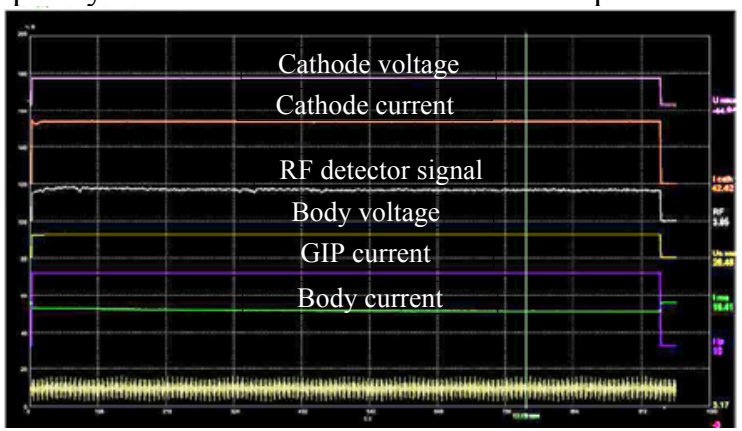

Fig. 2 Signal traces monitored during one of $1 \mathrm{MW} / 1000$ s pulse

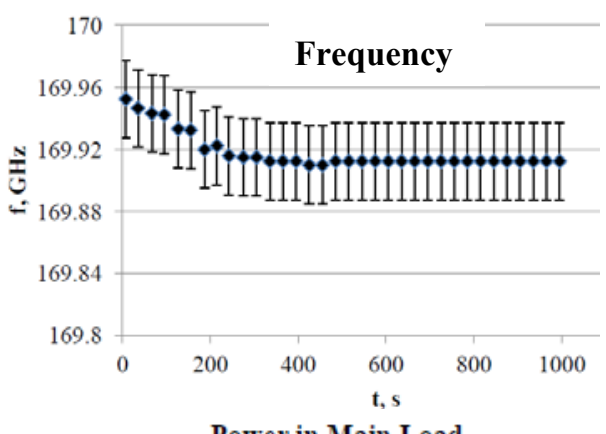

Power in Main Load

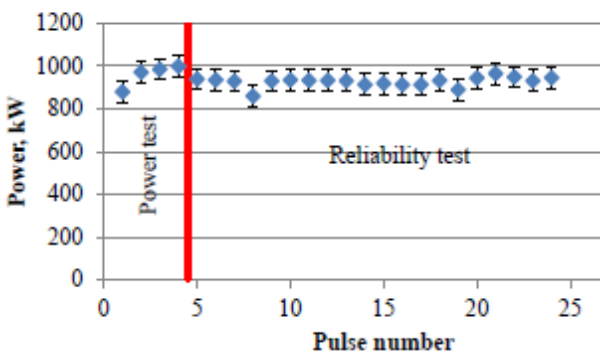

Fig.3 Statistics of frequency and power measurements for 500 s and 1000 s pulses

$\mathrm{X}$-ray emission was found to be a serious issue even under testing of the first serial gyrotron. Lead shielding placed directly around gyrotron collector was not sufficient to suppress X-ray dose to admissible limit in vicinity of gyrotron casing due to stray radiation fraction going inside gyrotron body and penetrating through its copper wall. Problem was sold by mounting of rubber sheets with lead filling about outer contour of the support structure.

Gyrotron requested by F4E with ancillary components was delivered to SPC, mounted into SCM and connected to powering and cooling systems in June 2017. Under series of initial experiments in JulyAugust 2017 at RF power of about $250 \mathrm{~kW}$ inherent misalignment of terminal spherical load reflector with respect to waveguide one was revealed, which resulted in nonuniform load overheating. To correct misalignment Gycom in September 2017 produced and shipped to Lausanne copper bellows. In November 2017 combination of much higher RF power/ pulse duration was managed to attain $(680 \mathrm{~kW} / 100 \mathrm{~s}$ and $880 \mathrm{~kW} / 10 \mathrm{~s}$ ) but further increase of pulse energy was blocked by vacuum impairment in the load accompanied by light protection.

Test showed that produced to that time modifications of the load and its pumping port could not solve completely issue of load interior vacuum impairment. Additionally problem had arisen of correct power calorimetric measurements. Personal of F4E and SPC works now together to solve the problems. Test hopefully will be prolonged in July 2018.

\section{Gyrotron system delivery issues}

In the ITER site only case of building B15 has been erected but none interior infrastructure (cooling, powering, air conditioning etc.) has been set up. Site is not ready yet for start of any gyrotron system installation. "First plasma" operation is now postponed to 2027. IO is going to move delivery start of Russian gyrotron systems from 2018 to the end of 2019 . To the moment of shipment implementation components of produced and passed the acceptance test gyrotron systems is to be stored in Gycom depositary being packed in the transport crates.

\section{Summary}

- $\quad$ Recently two gyrotrons systems for ITER ECH plant were manufactured and passed factory acceptance test successfully but being equipped with control system essentially deviating from the regular one

- Developing of regular control system for ITER $\mathrm{RF}$ power source is mainly delayed due to permanent changes in hardware and software initiated by IO and is waited now to be completed and tested in the end of this year

- Manufactured and tested gyrotron systems due to delay in ITER schedule are to be stored in Gycom depositary until at least end of 2019 when ITER site will hopefully be ready to accept package delivery and provide start of gyrotron system installation

- $\quad$ Analogue of $1 \mathrm{MW} / 170 \mathrm{GHz} / 1000$ s ITER gyrotron with agreed ancillary components was manufactured by Gycom under contract with F4E, passed factory acceptance test with the participation of F4E representatives and in June 2017 was shipped to Falcon facility of Swiss Plasma Center (SPC) in Lausanne

- $\quad$ Testing of Gycom gyrotron on site at SPC reveals problems with terminal load of the waveguide transmission line becoming evident by intensive outgassing accompanied by arc detection under increase of RF power or pulse duration Gyrotron test in SPC will be prolonged in July.

\section{References}

1. L. Popov et al. Super-High Power Gyrotrons for Electron-Cyclotron Plasma Heating // $10^{\text {th }}$ International Workshop "Strong Microwaves and Terahertz Waves: Sources and Applications" N. Novgorod - Moscow, July 2017

2. ITER_D_VJLBHF v1.1. FAT report on $1^{\text {st }}$ delivery RF DA RF power source 